\title{
Problems of thermonuclease detection for identifying Staphylococcus aureus in blood culture broths
}

\author{
G M Megson, D Law, L A Ganguli
}

\begin{abstract}
The detection of thermonuclease by the Oxford strain and eight clinical isolates of Staphylococcus aureus in a variety of bacteriological broths with and without added blood was examined using a toluidine blue-DNA-agar plate method. In Isosensitest, brain-heart infusion, tryptic soy, nutrient and gas-liquid chromatography broths (all of which do not contain liquoid) thermonuclease detection was uncomplicated. In Bactec broths (containing liquoid) detectable thermonuclease activity was greatly reduced in the absence of blood. The addition of $10 \%$ blood to the Bactec broths restored the activity. Liquoid was shown to be responsible for the inhibition of thermonuclease activity, and its effect could be neutralised by the addition of blood, albumin, or haemoglobin. In specimens containing no blood, or insufficient blood to neutralise the liquoid in culture broths, more has to be added to prevent false negative reporting of $S$ aureus. This can be done after growth at the time of thermonuclease testing.

Clinical consequences of delayed identification of $S$ aureus in routine blood cultures may be serious. The application of the thermonuclease test to blood culture broths is both fast and specific.
\end{abstract}

The differentiation of Staphylococcus aureus from coagulase negative staphylococci is important in clinical microbiology laboratories. Traditionally, the separation of $S$ aureus from coagulase negative staphylococci has been achieved using either the slide or tube coagulase tests; several commercially obtainable kits based on these tests are now available. ${ }^{1-3} \mathrm{~A}$ disadvantage of both the traditional and kit based tests is that they were developed specifically for the analysis of bacterial colonies on solid media, and the application of these techniques to broth cultures is time consuming and generally unreliable. ${ }^{14}$

The production of deoxyribonuclease (DNase) by staphylococci correlates well with the production of coagulase, which is linked with pathogenicity. ${ }^{3-8}$ Unfortunately, DNase production is not limited to staphylococci, and it has been shown that a variety of genera and even some coagulase negative staphylococci can be DNase producers. ${ }^{28}$
In 1971 Lachica et al showed that in addition to DNase, which is heat-labile, $S$ aureus also produces thermonuclease - a heat-stable endonuclease (micrococcal nuclease EC 3.1.4.7) which is unique to the species. ${ }^{8-11}$ Further to this a medium was developed which was suitable for the detection and approximate quantification of the enzyme and gave reliable results after four hours of incubation..$^{41213}$ Subsequent studies showed the high sensitivity and specificity of the thermonuclease (TNase) test and the usefulness of its application to routine blood culture bacteriology.5 ${ }^{1314}$ TNase results are normally interpreted after two hours of incubation, ${ }^{67}$ but in our hands positive TNase reactions from blood cultures are generally readable after as little as 20 minutes' incubation (data not shown).

\section{Methods}

The Oxford staphylococcus, a laboratory strain of $S$ epidermidis, and eight randomly chosen clinically important $S$ aureus isolates which had recently been grown from blood culture were used in the study. All bacterial strains were identified by catalase test, tube coagulase test, and Gram strain; further confirmation of identity was provided by API Staph biochemical test strips (API-BioMèrieux, Basingstoke, Hants).

The following liquid media were used: Isosensitest Broth (Oxoid Ltd); Bactec 6B, Bactec 7D, Bactec NR6A, Bactec NR7A (Becton Dickinson Ltd, Towson, Maryland, USA); nutrient broth (Oxoid); MuellerHinton broth (Oxoid); brain heart infusion broth (Lab-M Ltd, Bury, Lancs); GLC broth (Lab-M); tryptic soy broth (Difco Ltd, Detroit, Michigan, USA). Of these, only the Bactec media contain liquoid. All the dehydrated media were made according to manufacturers' instructions and autoclaved at $121^{\circ} \mathrm{C}$ for 15 minutes.

Toluidine blue/DNA agar was prepared according to the method of Lachica et al. ${ }^{11}$ The constituents were as follows: Trizma base (Sigma Chemicals, Poole, Dorset); Bacto DNA (Difco); toluidine blue (Sigma); and bacteriological agar number 1 (Oxoid). The medium was stored in $100 \mathrm{ml}$ aliquots at $4^{\circ} \mathrm{C}$ and, when required, was melted in a water bath and poured in $20 \mathrm{ml}$ amounts into standard $85 \mathrm{~mm}$ diameter Petri dishes. As TNase agar is sensitive to changes in media composition ${ }^{15}$ each batch of media and each experimental
Correspondence to: Mr G M Megson

Accepted for publication 24 April 1991 
Table 1 Detection of thermonuclease activity of isolates grown in Bactec and non-Bactec overnight broths with and without added blood

\begin{tabular}{lll}
\hline & TNase reaction class & \\
\cline { 2 - 3 } Broth type, with or without blood & Oxford strain & Eight clinical isolates \\
\hline Non-Bactec broths - blood & 4 & 4 \\
Non-Bactec broths + blood & 4 & 4 \\
Bactec broths - blood & 2 & 2 \\
Bactec broths + blood & 4 & 4 \\
\hline
\end{tabular}

Bactec broths were NR6A, NR7A, 6B and 7D. Non-Bactec broths comprised Isosensitest, nutrient, Mueller-Hinton, brain-heart infusion, tryptic soy and gas-liquid chromatography.

plate were quality control tested with overnight Isosensitest broths of coagulase negative staphylococci and the Oxford strain.

Six colonies from a blood agar plate $\left(37^{\circ} \mathrm{C}\right.$, aerobic) of the organism under test were suspended in $10 \mathrm{ml}$ of Isosensitest broth. Three drops of this dilute suspension were used to seed the $10 \mathrm{ml}$ broths, which were then incubated aerobically, unshaken overnight at $37^{\circ} \mathrm{C}$. Sterile defibrinated horse blood (Advanced Protein Products, Brockmoor, West Midlands) was added to selected bottles to a final concentration of $10 \% .^{15}$ Filter sterilised sodium polyanetholesulphonate (liquoid, Sigma) was added when required to give a final concentration of $0.035 \%$ as found in non-radiometric Bactec Broths NR6A and NR7A. When human haemoglobin (Sigma) was added, filter sterilised solutions in $0.9 \%$ saline were used to give a final concentration approximate to that found in lysed human blood $\left(150 \mathrm{~g} \mathrm{~L}^{-1}\right)$. Albumin (Blood Products Laboratory) was also added to simulate the concentration found in human blood $\left(45 \mathrm{~g} \mathrm{~L}^{-1}\right)$.

In the initial experiment all the clinical strains and the Oxford strain were grown in the full range of broths with and without added blood and thermonuclease tests were performed (table 1). Subsequently the effect of adding blood or liquoid to Isosensitest broths before and after growth of the Oxford strain was investigated (table 2) and the effect of different concentrations of haemoglobin and albumin on TNase activity noted (table 3 ).

Table 2 Effect on thermonuclease activity of addition of liquoid and blood to Isosensitest broths of $S$ aureus (Oxford strain) before and after growth

\begin{tabular}{|c|c|c|c|c|c|}
\hline \multirow[b]{2}{*}{ Tube No } & \multicolumn{5}{|l|}{ Addition of: } \\
\hline & $\begin{array}{l}\text { Liquoid before } \\
\text { inoculation }\end{array}$ & $\begin{array}{l}\text { Liquoid after } \\
\text { growth }\end{array}$ & $\begin{array}{l}\text { Blood before } \\
\text { inoculation }\end{array}$ & $\begin{array}{l}\text { Blood after } \\
\text { growth }\end{array}$ & TNase \\
\hline 1 & + & - & - & - & 2 \\
\hline 2 & - & \pm & - & - & 2 \\
\hline 4 & - & - & - & + & 4 \\
\hline 5 & + & - & + & - & 4 \\
\hline & - & + & - & + & 4 \\
\hline 7 & - & + & + & - & 4 \\
\hline & + & - & - & + & \\
\hline
\end{tabular}

Table 3 Effect on thermonuclease activity of addition of haemoglobin, albumin, and blood to overnight Isosensitest broths of $S$ aureus (Oxford strain) with added liquoid

\begin{tabular}{llllll}
\hline Tube No & Albumin & Haemoglobin $\dagger$ & Haemoglobin & Blood & TNase \\
\hline 1 & - & - & - & - & 2 \\
2 & - & - & - & + & 4 \\
3 & - & + & + & - & 4 \\
4 & - & - & - & - & 3 \\
5 & + & - & & & 3 \\
\hline
\end{tabular}

$+150 \mathrm{~g} \mathrm{~L}^{-1} ;{ }^{\star} 45 \mathrm{~g} \mathrm{~L}^{-1}$.
Table 4 Classification of thermonuclease reaction zone sizes

\begin{tabular}{lcl}
\hline Class & Zone size $(\mathrm{mm})$ & Zone intensity \\
\hline 1 & $6-7$ & Faint clear rim, not pink \\
2 & $7-10$ & Faint pink colour \\
3 & $10-12$ & Strong pink colour \\
4 & $>12$ & Strong pink colour \\
\hline
\end{tabular}

The TNase test was performed by pipetting 3-5 ml of overnight broth into a small, screw topped serum phial and heating for 15 minutes in a $100^{\circ} \mathrm{C}$ heating block. The broth was cooled, vortex mixed, and centrifuged at 3000 $\times g$ for 10 minutes. Holes of $6 \mathrm{~mm}$ in diameter were punched in the thermonuclease agar and filled with boiled supernatant. Plates were incubated in air at $37^{\circ} \mathrm{C}$ for two hours before the test was interpreted.

The zone sizes (diameter of pink zone including $6 \mathrm{~mm}$ well diameter) and reaction intensities for the four classifications were as shown in table 4 . These classifications were chosen as the observed zone sizes tended to fall naturally into the four groups.

\section{Results}

All broths showed a high turbidity after overnight incubation, indicating good bacterial growth. Initial experiments with coagulase negative staphylococci showed that negative TNase reactions (class 1 ) were observed in all the broths, either alone or supplemented with blood, haemoglobin, albumin or liquoid. In all three replications of each experiment the control inoculations gave a positive TNase reaction with the Oxford strain and a negative reaction with the coagulase negative staphylococci.

Thermonuclease activity was detectable in a variety of bacteriological broths containing the Oxford strain with and without added blood, but a strong positive reaction was seen in Bactec broths only in the presence of blood. The same pattern was observed with eight clinical blood culture isolates of $S$ aureus (table 1).

The addition of liquoid to Isosensitest broths containing the Oxford strain either before or after overnight incubation inhibited the detection of TNase. This inhibition was neutralised by the addition of blood either before or after incubation. The addition of blood in the absence of liquoid had no effect on TNase activity (table 2). The addition of albumin, haemoglobin, or blood to Isosensitest broths containing added liquoid resulted in inhibition neutralisation that was dependent on the concentration of the compound added (table 3).

\section{Discussion}

Despite an initial reduction in the incidence of $S$ aureus in the 1960 s and 1970s due to the introduction of $\beta$-lactamase resistant antibiotics, the staphylococcus is currently enjoying a return to prominence as a causative agent of septicaemia. ${ }^{16}$ Figures as high as $58 \%$ of nosocomial bacteraemias attributed to $S$ 
aureus have recently been reported. ${ }^{16}$ When repeatedly isolated from "at risk" patients coagulase negative staphylococci may be significant but recent reports suggest that this is the situation in only $1-10 \%$ of cases ${ }^{16}$ and that most coagulase negative staphylococci are introduced to blood culture broths at the time of sampling. ${ }^{5}$

As the morbidity and mortality associated with $S$ aureus are particularly high it is essential that in blood culture broths containing Gram positive cocci the differentiation between $S$ aureus and coagulase negative staphylococci is rapidly performed. None of the commercially available kits or the tube coagulase test is sufficiently sensitive or reliable to be used directly in this differentiation, ${ }^{14}$ but the thermonuclease test is.

We have shown that in Bactec broths (6B, 7D, NR6A and NR7A) containing liquoid ${ }^{17}$ the detectable thermonuclease activity of the Oxford strain and eight clinical strains of $S$ aureus was greatly reduced. The addition of blood (1:10 in broth) neutralised this effect as did haemoglobin and albumin. When haemoglobin was added at the same concentration as albumin $\left(45 \mathrm{~g} \mathrm{~L}^{-1}\right)$ it achieved the same degree of inhibition neutralisation. When the two compounds were added at the concentrations found in lysed human blood $\left(45 \mathrm{~g} \mathrm{~L}^{-1}\right.$ albumin, $150 \mathrm{~g} \mathrm{~L}^{-1}$ haemoglobin) the haemoglobin had a greater effect.

The fact that the addition of liquoid to Isosensitest broths of $S$ aureus could reduce thermonuclease activity after overnight growth, and that this effect could be neutralised by addition of whole blood or blood components either before or after growth, is evidence for the process being an inhibition of enzyme activity rather than an effect on enzyme synthesis or transport. A possible explanation is that liquoid binds a proportion of the TNase enzyme thus preventing its detection. The addition of further protein in the form of blood, albumin, or haemoglobin sets up a competitive association system, resulting in a dynamic equilibrium between the individual components. Hence, if a large proportion of protein is added to the system then more of this associates with the liquoid, thus releasing more active TNase.

In normal adult blood cultures in which 3-5 $\mathrm{ml}$ of blood is injected into each phial there will be sufficient organic material to neutralise the liquoid and allow TNase to be detected. In paediatric blood cultures, where only small volumes of blood may be available, or in specimens such as peritoneal dialysis fluid, joint fluid or ascitic fluid, especially when clot formation has occurred, there may not be enough protein to neutralise the effect of liquoid. This may lead to difficulty interpreting the test or delayed reporting of $S$ aureus isolation.

The manufacturers of the Bactec systems recommend the addition of blood to Bactec broths to facilitate the growth of liquoid sensitive and fastidious organisms. We support this recommendation and note that the addition of blood to Bactec broths containing liquoid, either before or after growth, will also prevent the occurrence of false negative thermonuclease tests. The could effectively be achieved by adding $0.5 \mathrm{ml}$ of sterile defibrinated horse blood to a $5 \mathrm{ml}$ aliquot of broth withdrawn for TNase testing. As the addition of blood has no adverse effects on the TNase test this should be performed on all broths containing liquoid and lacking sufficient blood for reliable TNase detection.

We thank Drs D B Drucker, M G L Keaney, and D W Denning for reviewing the manuscript and Miss J Elliott for helpful discussions.

1 Hamoudi AC, Hribar MM. Evaluation of a direct identification method for Staphylococcus aureus from blood culture broth. J Clin Microbiol 1988;27:1404-5.

2 Rossney AS, English LF, Keane CT. Coagulase testing compared with commercial kits for routinely identifying Staphylococcus aureus. J Clin Pathol 1990;43:256-62.

3 Berke A, Tilton RC. Evaluation of rapid coagulase methods for the identification of Staphylococcus aureus. J Clin for the identification of Stapl

4 Zarzour JY, Belle EA. Evaluation of three test procedures for identification of Staphylococcus aureus from clinical identification of Staphylococcus aure

5 Ratner HB. Thermonuclease test for same-day identification of Staphylococcus aureus in blood cultures. J Clin Microbiol 1985;21:995-6.

6 Madison BM, Baselski VS. Rapid identification of Staphylococcus aureus in blood cultures by thermonuclease testing. J Clin Microbiol 1983;18:722-4.

7 Menzies RE. Comparison of coagulase, deoxyribonuclease and heat-stable nuclease for identification of Staphylococcus aureus. J Clin Pathol 1977;30:606-8.

8 Sneath PHA, ed. Bergy's manual of systematic bacteriology. Ninth ed Vol 2. Section 12. Baltimore: Williams and Wilkins, 1986 .

9 Lachica RVF, Hoeprich PD, Genigeorgis C. Nuclease production and lysostaphin susceptibility of Staphyloproduction and lysostaphin susceptibility of Staphylococcus aureus and othe

10 Cuatrecasas P, Fuchs S, Anfinsen CB. Catalytic properties and specificity of the extracellular nuclease of Staphylococcus aureus. J Biol Chem 1967;242:1541-7.

11 Lachica RVF, Genigeorgis C, Hoeprich PD. Metachromatic agar-diffusion methods for detecting staphylococcal nuclease activity. Appl Microbiol 1971;21:585-7.

2 Gudding R. Differentiation of staphylococci on the basis of nuclease properties. J Clin Microbiol 1983;18:1098-101.

13 Rigby A. Thermonuclease testing: the rapid identification of Staphylococcus aureus in blood culture. Med Lab Sci 1986;43:196-8.

14 Koneman EN, Allen SD, Dowell SR, Janda WM, Sommers HM, Winn WC. Colour atlas and textbook of diagnostic microbiology. Third edn. Philadelphia: J P Lippincott, 1988.

15 Faruki H, Murray P. Medium dependence for rapid detection of thermonuclease activity in blood culture detection of thermonuclease activity in
broths. J Clin Microbiol 1986;24:482-3.

16 McGowan JE. Septicaemia: changing patterns of causative organisms and underlying conditions. In: Shanson DC, ed. Septicaemia and endocarditis-clinical and microbiological aspects. Oxford: Oxford University Press, 1989:5-48.

17 Stuart RD. The value of liquoid for blood culture. J Clin Pathol 1948;1:311-14. 